\title{
Spatial probability learning in the Virginia opossum'
}

\section{JOHN H. DOOLITTLE. Sacramento State College. JON WEIMER. Denver Veterans Administration Hospltal, Denver, Colonado}

Virginla opossums were given 600 trials in a $T$-maze on a $70-30$ spatial pmbabillty problem. The opossums maximized the percentage of their responses to the $70 \%$ alternative. choosing it on inore than $90 \%$ of the trials at asymptote. The learning curve of opossums did not differ from the learning curve of a control group of rats. It was concluded that in the Bitterman fish-rat dichotomy. the opessum is classified as a rat on this problem.

Bitterman (1965) has concluded that for tasks of habit reversal and probability learning all species of animals can be classified by their performance as either rats or fish. A species is classified as rat if it shows maximizing or nonrandom probability matching and progressive improvement in habit reversal and as fish if it shows random probability matching and failure of progressive improvement in habit reversal. This system has been used to classify the earthworm, cockroach, fish, turtle, pigeon, rat and monkey. Bitterman (1965) has urged the extension of the comparisons to phyla and classes not yet classified, as has Warren (1965), as a means of assuring that the results are not artifacts of the species selected for study.

Herring, Mason, Doolittle, \& Starrett (1966) have pointed out that the Virginia opossum (Didelphis Virginiana), as a marsupial and transitional form between the reptiles and the mammals, should be the subject of comparative learning studies. Friedman \& Marshall (1965) demonstrated progressive improvement by the Virginia opossum in a habit reversal task, leading it to be classified as a rat on this task. The present study investigated the performance of the Virginia opossum on a probability learning task and included a comparison group of rats.

\section{METHOD}

The Ss were five experimentally naive Virginia opossums, three males and two females, and five experimentally naive SpragueDawley rats, all males. The opossums were approximately 6 months of age and the rats 4 months of age initially. The apparatus for opossums consisted of a $\mathrm{T}$-maze of black plastic with start and goal boxes of 6 in. $\times 6$ in. $\times 10$ in. and a choice point os 6 in. $\times 6$ in. $\times 6$ in. For five days prior to the beginning of the experiment, $S s$ were adapted to a $15 \mathrm{~min}$ per day feeding schedule. The opossums were maintained on this feeding schedule while the rats were maintained at $80 \%$ of their ad lib body weight. On the fifth day, each $S$ was given five nonreinforced trials to determine which arm of the maze was preferred.

For 30 days, each $\mathrm{S}$ was given 20 massed trials per day, the preferred arm being randomly reinforced on $30 \%$ of the trials and the non-preferred arm on $70 \%$ of the trials. The distribution of reinforcements was determined by the use of a table of random numbers, with the restriction that at least one of the responses to the $30 \%$ alternative be reinforced in each block of five trials. Each reinforcement consisted of $1 / 2$ of an $M$ \& $M$ candy for the opossums and $\mathrm{a} 0.1 \mathrm{~g}$ food pellet for the rats. The arm initially entered by the $\mathbf{S}$ on each trial was recorded as the preferred arm for that trial. The correction method was used so that if the arm initially entered by the $S$ did not contain the reinforcement, the $S$ was allowed to enter the non-preferred arm so that each trial terminated with a reinforcement.

\section{RESULTS}

For each $S$ the daily percentage of initial preferences for the $70 \%$ arm was computed. These percentages were averaged over all the $S s$ in the group and over three-day blocks to provide a relatively stable index of performance. Fig. 1 presents graphs of the average percentages of preference over the 3 day blocks of 60 trials for the opossums and the rats. Using sequential probability ratio tests (Hoel, 1954), all Ss met the criterion of maximizing. Also, it is clear by inspection of the graphs that the rats and opossums performed similarly and that both tended to maximize on this problem.

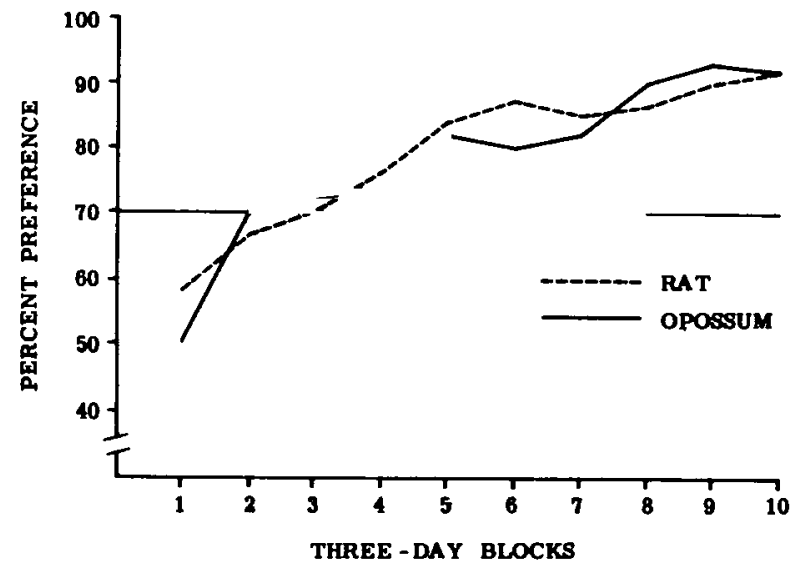

Fi. 1. Preference of nt and oposium for the $70 \%$ arm of the maze over trial blocks.

\section{DISCUSSION}

The results indicate that the Vinginia opossum can be classified as a rat according to Bitterman's (1965) rat-fish dichotomy for spatial probability learning. Another group of rats run on a spatial probability learning task by Bitterman, Wodinsky, \& Candland (1958) reached the $90 \%$ or above level of responding after only six days as compared with 22 days for the present group of rats. This difference can be explained by the fact that the rats of Bitterman et al (1958) had received 40 days of training on a visual probability learning problem prior to attempting the spatial task. In addition, there were apparatus and procedural differences between the two studies.

The similarity of rats and opossums was greater than would have been predicted from habit reversal studies in which the performance of rats was superior to the performance of opossums (Friedman \& Marshall, 1965). In addition, comparisons between another marsupial, Trichosurus Vulpecula, and rats on performance in the Hebb-Williams maze (Pollard \& Lysons, 1967) showed the rats to be markedly superior. Perhaps the spatial probability performance is an insensitive measure of some of the species differences detected by habit-reversal or Hebb-Williams maze performance. Supporting this hypothesis is the unexpected fact that on probability tasks monkeys maximize less consistently than rats (Wilson, Oscar, \& Bitterman, 1964).

\section{REFERENCES}

BITTERMAN, M. E. Phyletic differences in learning. American Psychologist, $1965,20,396-410$.

BITTERMAN, M. E., WODINSKY, J., \& CANDLAND, D. K. Some comparative psychology. American Joumal of Psychology, 1958, 71, 94-110.

HERRING, F. H., MASON, D. J., DOOLITTLE, J. H. \& STARRETT, D. E. The Virginia opossum in psychological research. Psychological Reports, $1966,19,755-757$.

HOEL, P. G. Intmoduction to mathematical statistics New York: Wiky, 1954. POLLARD, J. S., \& LYSONS, A. M. Possums in the closed field test. Animal Behavior, 1967, 15, 129-133.

WARREN, J. M. The comparative psychology of kearning. Annual Review of Psychology, 1965, 16, 95-118.

WILSON, W. A., OSCAR, M., \& BTTERMAN, M. E. Probability-learning in the monkey. Quarterty Journal of Experimental Psychology, 1964, 16, 163-165.

\section{NOTE}

1. This investigation was supported by Public Health Service Research Grant MH14176-01 and by the Veterans Administration. 